\title{
Inhalt
}

Jürgen Schiewe

Vorwort -1

\section{Erkenntnis und Sprache in Goethes Naturwissenschaft [1974] — 6}

Einleitung -6

I Einheit und Unterschiedenheit der Natur und ihr Analogon in den beiden

Typen des synthetischen und analytischen Erkenntnis- und Sprachverhaltens. - Goethes Versuche zu ihrer Vermittlung in den Formen seiner wissenschaftlichen Darstellung - 15

1 Der Aufsatz Naturlehre (1789). - Erste Entfaltung des Problems - 15

2 Systematische Klassifikation und Nomenklatur. - Zu Linnés Systema Naturae 25

3 Anpassung an den wissenschaftlichen Darstellungstyp. - Goethes Arbeit über den Zwischenkieferknochen - 35

4 ,Genetische Abstraktion`. - Zur Begriffsbildung Goethes in den Aufsätzen zur vergleichenden Anatomie. Synonymenvariation und Nomenklaturtafel 37

5 Mimetische Darstellung eines gegliederten Kontinuums. - Zur Metamorphose der Pflanzen - $\mathbf{5 1}$

6 Das Prinzip der ,stetigen Reihe‘. - Bemerkungen zur Form der Farbenlehre -66

7 Die,Vermittlung von Idee und Erfahrung, Subjekt und Objekt, und die Verbindung von Enthusiasmus und Sachlichkeit. - Überlegungen Goethes zur Darstellungsform der Metamorphose der Pflanzen — 71

8 Goethes, Orangenstil'. Die lockere Reihe der Gattungen und Perspektiven. - Zur Form der Morphologischen Hefte und der Principes de Philosophie Zoologique — 91

9 Der relative Wert der Termini als Ausdruck von,Vorstellungsarten‘. Arbiträre Symbole und Begriffs-Schemata als Darstellungsmittel. - Zu Vorarbeiten zur Morphologie und Bildungstrieb -100

II Goethes Warnung vor der Sphärenvermengung in der Naturwissenschaftssprache und seine Idee einer universellen Symbolik — $\mathbf{1 1 7}$

III Überlegungen Goethes zur institutionalisierenden Wirkung der Naturwissenschaftssprache und zur Bedeutung des wissenschaftlichen Darstellungstypus für die Rezeption — 148

Ist die Sprache ein selbständiger Faktor der Wissenschaftsgeschichte?

Über die Anstößigkeit unerwarteter Sprache [1990/1994] — 154 
Aspekte einer Geschichte der deutschen Naturwissenschaftssprache und ihrer Wechselbeziehung zur Gemeinsprache [1984/1986] — 170

Der Übergang vom Gelehrtenlatein zur deutschen Wissenschaftssprache. Zur frühen deutschen Fachliteratur und Fachsprache in den naturwissenschaftlichen und mathematischen Fächern (ca. 1500-1800) [1983/1986] 202

Paracelsus als wissenschaftlicher Schriftsteller

Ist die deutsche Sachprosa eine Lehnbildung der lateinischen

Schriftkultur? [1994] 233

\section{Nachwort}

Gottfried Wilhelm Leibniz: Unvorgreifliche Gedanken, betreffend die Ausübung und Verbesserung der deutschen Sprache [1983] — 274

Die Produktivität eines Phantoms

Lichtenberg, das Phlogiston und die neue Chemie Lavoisiers [1988/1994] 291

Brauchen wir eine vergleichende europäische Sprachgeschichte? Latein als Hintergrund und Untergrund unserer Wissenschaftssprache [1999] 310
„Alles ist Blatt“
Über Reichweite und Grenzen der naturwissenschaftlichen Sprache und Darstellungsmodelle Goethes [1988] — 335

Zur Metaphorik der naturwissenschaftlichen Sprache

Dargestellt am Beispiel Goethes, Darwin und Freuds [1978] — 355

\section{Nachwort}

Carl Gustav Jochmann: Briefe eines Homöopathischgeheilten an die zünftigen Widersacher der Homöopathie [1994] 373

Die Metaphorik Darwins und Freuds

Überlegungen zu ihrer möglichen Wirkung [1979/1986] — 390

Zur Terminologie der Psychoanalyse [1973] — 414 


\section{Grenzfall der Literatur?}

Freuds Kleiner Hans als linguistische Kriminalnovelle [1994] — 447

Wird unser Land zweisprachig?

Vorsichtige Überlegungen zur Geschichte und Zukunft des Deutschen [2008] 462

\section{Populäre Sachprosa und naturwissenschaftliche Sprache}

Dargestellt am Beispiel eines Postversandbuchs vom Verlag Das Beste und eines erzählerischen Sachbuchs von Hoimar von Ditfurth [1980] — 475

\section{Blickprägung und Tatsache}

Veranschaulichungsstufen der Naturwissenschaften - von der hypothetischen Skizze bis zum öffentlichen Idol [1998] — 495

\section{Visualisierung versus Sprache}

Die Spirale als Metapher oder als Illustration der Phänomenologie des Geistes [1994] 519

\section{Das Demokratisierungsparadoxon}

Die zweifelhaften Vorzüge der Verwissenschaftlichung und Verfachlichung unserer Sprache [1984/1986] — 537

Was spricht dafür, das Deutsche als Naturwissenschaftssprache zu erhalten? [2001] 557

\section{Wissenschaftssprache - Umgangssprache - Politikberatung}

Drei sprachliche Felder - drei Diskurse [2016] — 576

\section{Literaturverzeichnis $\mathbf{5 8 8}$}

Drucknachweise - 615

Sachregister -617

Namenregister -624 
